\title{
Abrasive wear in hard thin films coated dies in hot extrusion aluminum
}

\author{
J. Herrera ${ }^{1}$, D. Martínez ${ }^{*}$, R. González ${ }^{2}$ and J. Rodríguez ${ }^{1}$ \\ ${ }^{\prime}$ Facultad de Ingeniería Mecánica y Eléctrica, Universidad Autónoma de Nuevo León., A.P. 149-F, 66451 San Nicolás de los Garza, N.L., \\ México. ${ }^{2}$ Facultad de Ingeniería Civil, Universidad Autónoma de Nuevo León, A.P. 149-F, 66451 San Nicolás de los Garza, N.L. México \\ Recibido 28 de Febrero de 2012, aceptado 6 de Marzo de 2012
}

\begin{abstract}
Abrasive wear resistance of hot extrusion AISI H13 coated dies used to produce extruded aluminum micro multivoid tubes was studied. In this process, aluminum and dies are constantly under high friction conditions producing premature die wear; aluminum or lubricant adherence on die surface layer, is caused by this phenomenon with product rejection as a consequence. The hot extrusion dies most important properties are hot hardness, wear resistant and surface finishing. Extrusion dies coated with hard thin film coatings by physical vapor deposition, PVD and chemical vapor deposition, CVD, were utilized and thermal diffusion treatment as an alternative. The thin film coatings mechanical properties, nano indentation, and SEM surface analysis were performed to characterize coatings and dies. The wear mechanism was determined and it is affected by the die contact surface layer finished by electropolishing and the dies coated with thermal diffusion treatment was the most resistant condition to the wear process due to the presence of $\mathrm{V}$ and $\mathrm{Nb}$ carbonitrures.
\end{abstract}

Keywords: Wear, hard coatings, extrusion, nano indentation.

\section{Introduction}

Obtaining multi-cavity tubes (MMV) is performed by means of extrusion involves forcing the passage of material through a die, using high pressure, to obtain a particular profile. The raw material is subjected to mechanical stress, heating, pressure, and strain and cooling. The process involves placing the ingot at a temperature inside the container of the press for its compression, this is down to flow through the mold of four cavities located in an interval temperature between $300{ }^{\circ} \mathrm{C}$ and $350^{\circ} \mathrm{C}$, to an interval speed between $38-42$ $\mathrm{m} / \mathrm{min}$ (see Figure 1). The extrusion dies are made of high speed steel tools and are important components in the extrusion process. The important factors in an extrusion die are the die angle and shape of the orifice [1-5]. For smaller angles, the surface area of the die increases, as well as friction at the interface die - billet, while a large angle causes more turbulence in the flow of metal during the area reduction, and increase in the piston. The optimum angle for each die depends on the work material, billet temperature and lubrication.

The orifice shape in the die affects the required pressure of the piston in an extrusion operation. According to the process, the raw material and the female are in constant friction and therefore wear is presented as a natural effect of this phenomenon. The most important properties of the dies are high wear resistance, high hot hardness and high thermal conductivity to remove heat from the process. Some carbides such as TiCN are used as coatings when high production speeds required, given long life and good dimensional control [5-8].

The main problems that have arisen during the production of MMV tubes are: wear of the female covered and adhesion of aluminum or lubricant on the walls of the female, producing off-specification products dimensional stripes on the surface of the

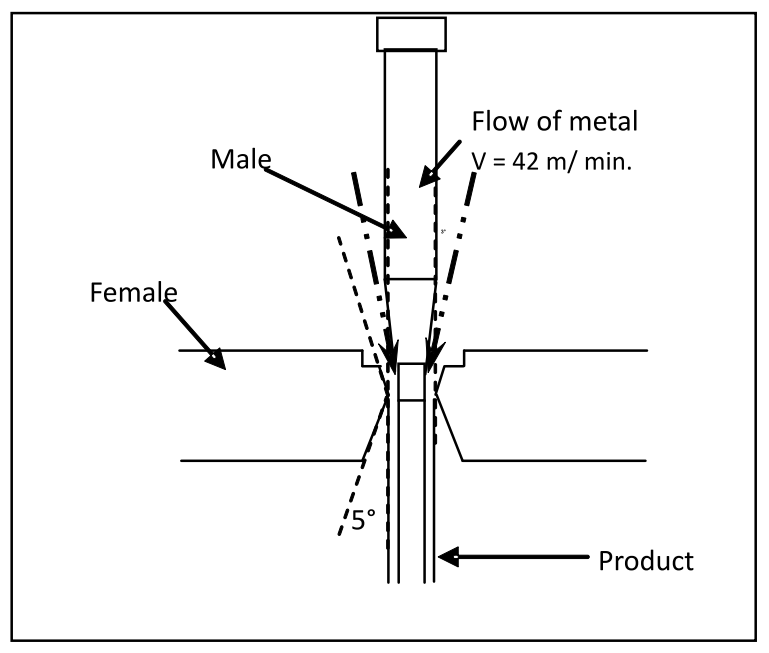

Figure 1. Squeme of the area through which flows the aluminum.

product change females and constant production downtime. The constant friction which is aluminum on the die is the main cause of wear of the coating was also affected by temperature. Use or replacement of the dies is one of the problems has been widespread in the extrusion process. The tooling are the base or most important factor in the process, since some of them will yield the desired aluminum profile, in addition to speed, preheat temperature of billets and process pressures used, the material base of the tooling, design parts, mechanical properties and coating material on the dies.

Wear presented in the dies mainly occurs in the cavity, being more generalized in the area of lower and upper echelon step, areas that are submitted to constant variations of temperature, friction and pressure exercised by the metal flowing through that area [9-11]. See Figure 1. The objective of this study is to evaluate the mechanism of wear that present the die coated female employees in the hot extrusion process for 
aluminum alloys, evaluating the damaged surface coating through techniques of optical and electronic microscopy and propose alternatives to extend the life of them.

\section{Experimental procedure \\ 2.1 Materials}

We used a AISI H13 steel (wt\%): Fe-0.383C$1.05 \mathrm{Si}-0.38 \mathrm{Mn}-5.2 \mathrm{Cr}-1.16 \mathrm{Mo}-0.18 \mathrm{Ni}$ as base metal in the female part (Figure 2). In the same steel were deposited the coatings to be evaluated. The classification of samples with different coatings and conditions of use are shown in Table 1. Was used the SEM-EDS technique to identify compounds of the coatings.

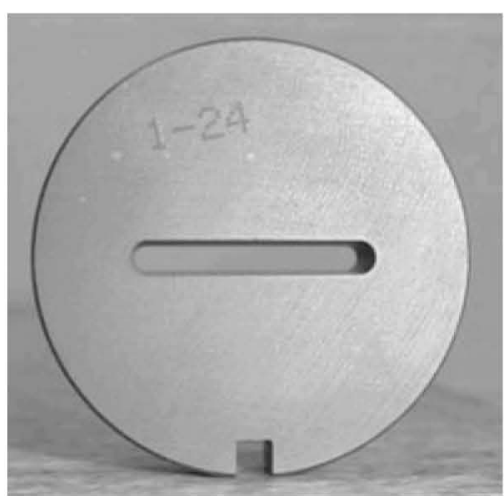

Figure 2. Female of extrusion of flat tube (MMV).

Table 1. Sample classification and coating used.

\begin{tabular}{|c|c|cc|c|}
\hline Sample & $\begin{array}{c}\text { Deposition } \\
\text { Type }\end{array}$ & \multicolumn{2}{|c|}{ Composition } & Condition \\
\hline A & CVD & Multilayer; Ti (C,N) & $\mathrm{Al}_{2} \mathrm{O}_{3}$ & Damage \\
\hline B & CVD & Multilayer; Ti (C,N) & $\mathrm{Al}_{2} \mathrm{O}_{3}$ & Damage \\
\hline C & CVD & Multilayer; Ti (C,N) & $\mathrm{Al}_{2} \mathrm{O}_{3}$ & New \\
\hline D & PVD & TiAlN & Damage \\
\hline E & TD & $(\mathrm{V} / \mathrm{Nb})(\mathrm{C}, \mathrm{N})$ & Used \\
\hline
\end{tabular}

\subsection{Experimental conditions}

The die assembly is performed at room temperature. This consists of a "die carrier", "carrier plate spiders", "female" (see Figure 2) and "male." Before going to the press, they are submitted to a preheating from $398{ }^{\circ} \mathrm{C}$ and $426^{\circ} \mathrm{C}$. The operating conditions and lifetimes of the specimens found in the product damage and die are described in Table 2 .

\subsection{Metalografic Analysis}

The metallographic analysis of the parts in each of the conditions obtained consisted of cutting each of the specimens with a diamond disc $330 \mathrm{CA}$. In all parts to be studied was followed the same process of cutting, mounting, polishing and attack. The pieces were cut into four slices to obtain two specimens of dimensions of $9.52 \mathrm{~mm}$ wide $x 15.87 \mathrm{~mm}$ of long and $4.76 \mathrm{~mm}$ in thickness and two specimens of $17.46 \mathrm{~mm} \times 15.87 \mathrm{~mm}$

Table 2. Experimental conditions used.

\begin{tabular}{|c|c|c|c|c|c|c|}
\hline Sample & $\begin{array}{c}\text { No. } \\
\text { Coating }\end{array}$ & $\begin{array}{c}\text { No. } \\
\text { Pickling }\end{array}$ & Test & $\begin{array}{c}\text { Number of } \\
\text { extruded } \\
\text { ingots }\end{array}$ & Defects & $\begin{array}{c}\text { Final } \\
\text { Condition }\end{array}$ \\
\hline A & 1 & 0 & 1 & 72 & scratch & $\begin{array}{c}\text { Coating } \\
\text { wear } \\
\text { cavities }\end{array}$ \\
\cline { 4 - 7 } & 1 & 0 & 1 & 84 & scratch & Worn \\
\hline C & 1 & 0 & N/A & N/A & N/A & $\begin{array}{c}\text { Good } \\
\text { condition }\end{array}$ \\
\hline D & 3 & 2 & $\begin{array}{c}2 \\
\text { (Polished })\end{array}$ & 18 & scratch & $\begin{array}{c}\text { cavities and } \\
\text { loss of } \\
\text { coating }\end{array}$ \\
\cline { 4 - 6 } & & $\begin{array}{c}3 \\
\text { (Polished) }\end{array}$ & 3 & scratch & scratch \\
\hline E & 1 & N/A & N/A & 81 & N/A & $\begin{array}{c}\text { Good } \\
\text { condition }\end{array}$ \\
\hline
\end{tabular}

x $9.52 \mathrm{~mm}$ in thickness. See Figure 3. To reveal the microstructure was used Picran known as reactive compound per $100 \mathrm{ml}$ of ethyl alcohol and $4 \mathrm{ml}$ of picric acid and $98 \mathrm{ml} \mathrm{Nital} \mathrm{composed} \mathrm{of} \mathrm{ethyl} \mathrm{alcohol}$ and $2 \mathrm{ml}$ of nitric acid, the mixture of acids was carried out at rates 1-1, the piece is placed in contact with the reagent for 5 seconds, washed, and dried alcohol applied.
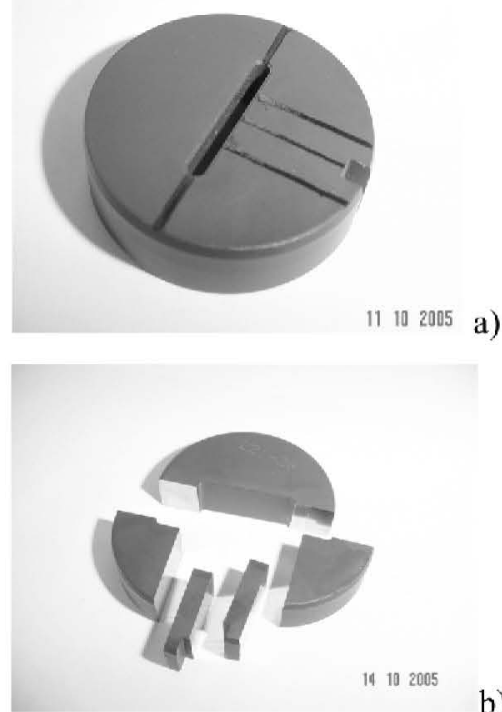

b)

c)

Figure 3. - a) Traces of cross sections, b) Cuts made with diamond disc and c) Specimen used for metallographic analysis. 


\subsection{Microhardness}

Microhardness tests were performed on the specimens studied before and after being tested in the extrusion process, vickers hardness was used, the loads used were $25 \mathrm{gr}$. in the area near the coating and $200 \mathrm{~g}$ in the base metal was determined microhardness profile in the area where occurs the most loss of material.

\subsection{Nano indentation}

In the nanoindentation test in thin layers, it is necessary to use very low loads (tenths of $\mathrm{mN}$ ) to avoid the influence of substrate. Generally, the criteria is accepted that the indenter should penetrate no more than $10 \%$ in the thickness of the layer to avoid the influence of substrate on hardness value of the own layer. The measurement of nanoindentation involves a continuous registration of the displacement of indenter (depth) and the applied load [12]. Test was determined by Berkovich, which consists of the application of a load $(<1 \mathrm{~N})$ on the surface of the test material using a printer in the shape of pyramid with a triangular base and apical angle of 65.27 degrees, see Figure 4 . The matrix was $25 \times 25$ measurements.

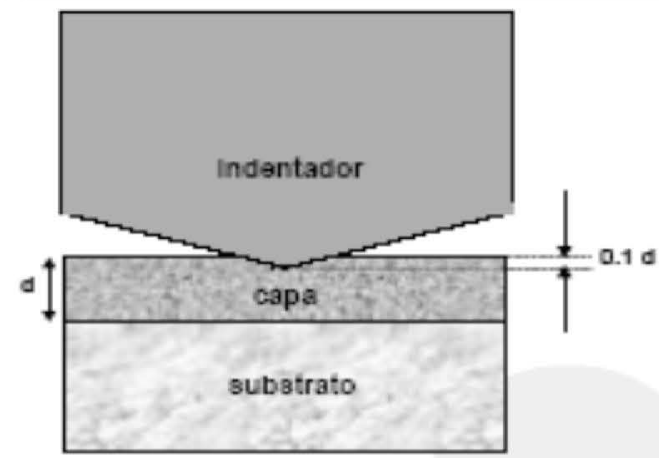

a)

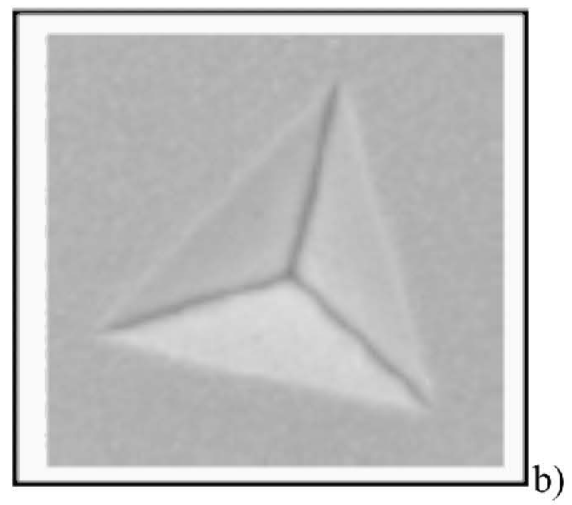

Figure 4 -a) The indentation depth must not exceed $10 \%$ of the thickness of the layer, so that the measures of hardness and elastic modulus are not influenced by the substrate. b) indentation with Berkovich tip [12]

\section{Results and discussion}

\subsection{Area Damage}

Figure 5 shows the images taken in the scanning electronic microscope of die $\mathrm{B}$ used in the hot extrusion process. Wear presented in the dies is observed in the cavity, being more generalized in the area of lower and upper echelon step, areas that are subject to constant variations in temperature, friction and pressure exerted by the metal flowing through that area. The coating material being in contact with the metal in the plastic state is the one who has to endure the constant friction and thus is the first affected by wear, causing or promoting product defects. Once the coating disappears steel and base metal is exposed to the aggressions of the flow causing further wear and total loss of the piece. The superficial projections or rough surface to deform plastically and finally come to weld due to high local pressures. As the sliding continues, these bonds are broken producing cavities on a surface, projections on the other, and tiny abrasive particles, all of which contribute to increased wear of the surfaces.

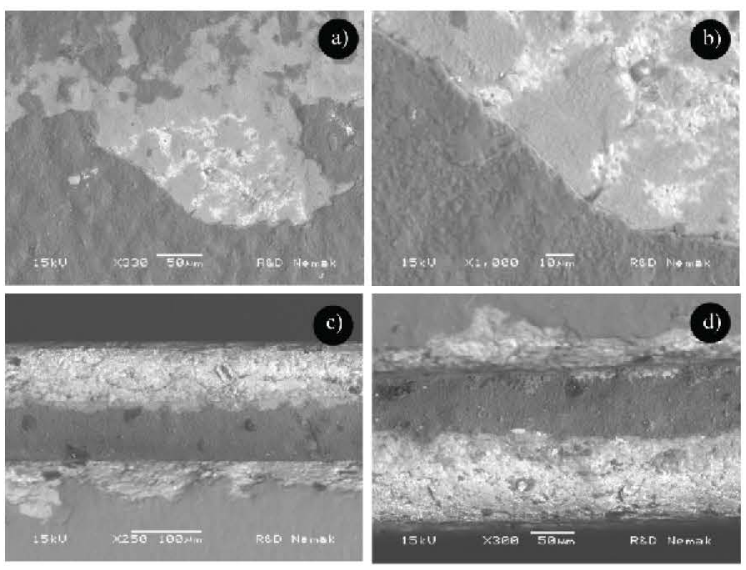

Figure 5 .- a) and b) show surface coatings die B while images c) and d) show the edges by which aluminum enters when it is formed.

\subsection{Microstructural Analysis}

Figure 6 shows some images of the samples analyzed. The microstructure of steel consists of a matrix of tempered martensite and the presence of fine carbides generated by the presence of microalloying elements. Figure $6 \mathrm{a}$ shows the coating which appears as a clear film. The images were taken in the area of greatest damage. Figure $6 \mathrm{~b}$ shows how the coating disappears, leaving some areas bare steel, but other remains intact. The average thickness of the layer CVD coating of specimen $\mathrm{C}$ is $6 \mathrm{~m}$, is the sum of the $\mathrm{TiCN}+\mathrm{Al}_{2} \mathrm{O}_{3}$ layer, as seen in Figure 7. This image shows a surface protuberance is a board which creates a discontinuity in the profile of the coating, this is caused in the EDM machining of the die base metal, this protuberance disappears in the die and worn, as shown in Figure 6. This was also observed in the dies with $P V D$ coating and TD. 

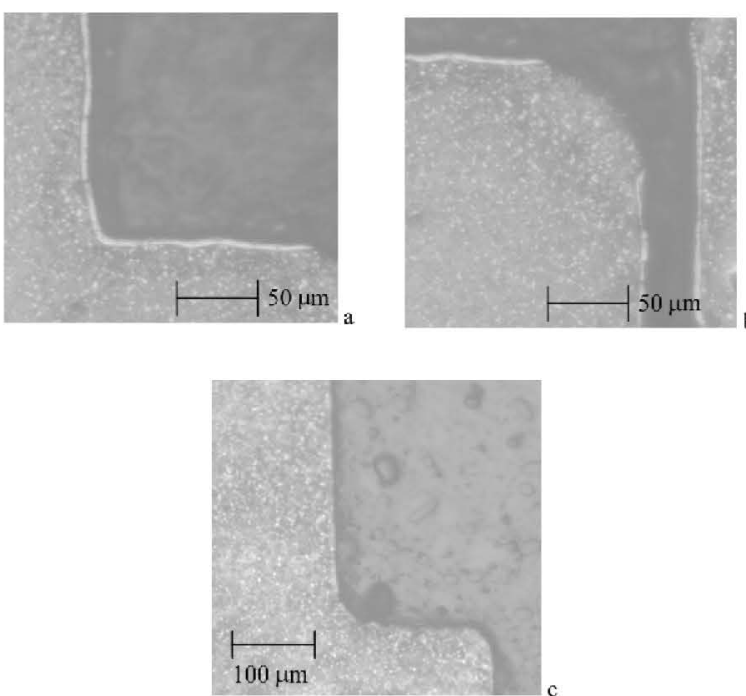

Figure 6. - a) and b) Metallography conducted on the die B CVD coated in the area of greatest damage, step less to $200 \mathrm{x} .6 \mathrm{c}$ ) die D PVD worn to $100 x$. Cross section.

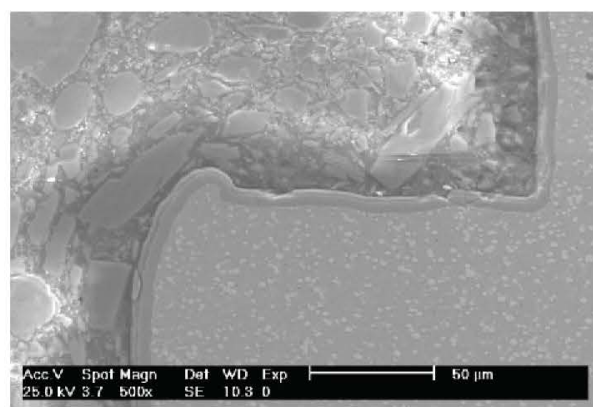

(a)

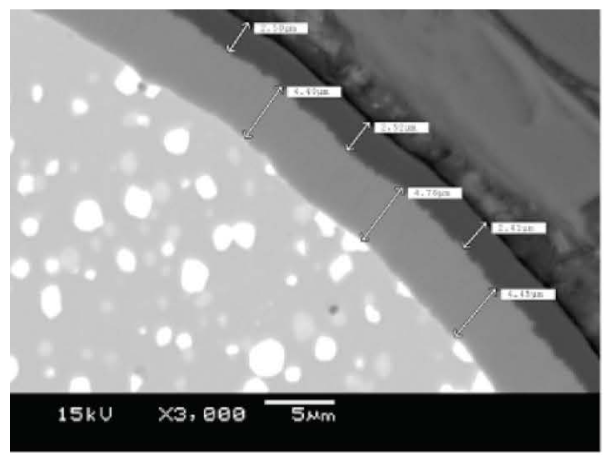

(b)

Figure 7. - (a) Zone of the upper step, given a new die (C) coated CVD. (b) Thickness of TiCN + Al2O3 layer.

\subsection{Microhardness}

Figure 8 shows the microhardness profile of the subsurface to the base metal of the specimens to different conditions. There is a softening of the sample CVD worn to a depth of $350 \mathrm{~m}$, this shows that the base metal is affected by temperature and with high friction due to contact with aluminum, damage that is seen in Figure 5. The PVD coating exhibits the same behavior at the same depth, but this material presents high values of hardness from the subsurface, this is because there is a high plastic deformation by the mechanical work on the surface. In the case of the TD specimen used provides a constant microhardness profile from the subsurface to the base metal, is not apparent softening to deposit the coating and to carry out the treatment by diffusion.

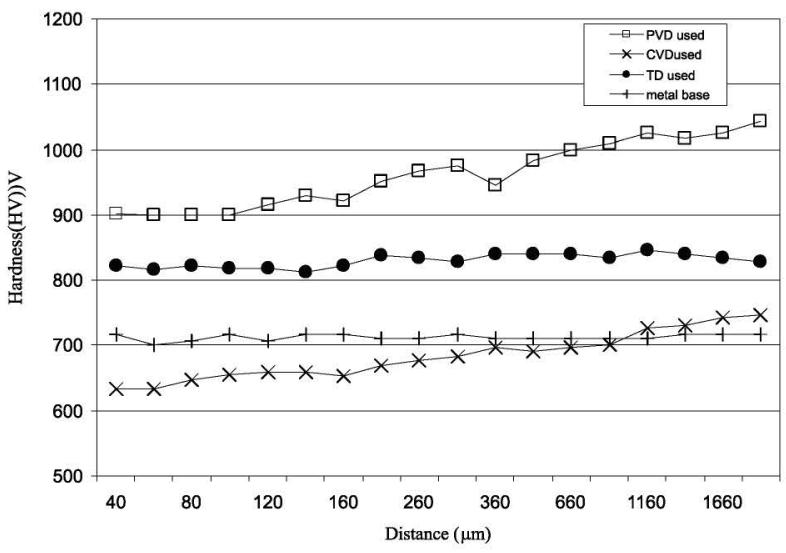

Figure 8. Microhardness profile of the subsurface to the metal base of the specimens to different conditions.

\subsection{Nano indentation}

The results of the nano indentation test samples were obtained for new CVD coated (C) and TD (E), Figure 9 shows the relationship of hardness against depth of penetration of the coating layer, is a trend in the sample of CVD to reduce the hardness with increasing penetration depth, Figure 9a, this can be due to the heterogeneity of the alumina deposit where the average thickness of $2.5 \mathrm{~m}$, see Figure 7. In the graph of Figure $9 \mathrm{~b}$ clearly shows the trend of the hardness in the subsurface layer of the TD to remain stable, this behavior was also found in the microhardness test (HV), surface treatment creates a layer of carbides nitrides $\mathrm{V} / \mathrm{Nb}$ uniforms that show a capacity of not being deformed by the mechanical work, see Figure 10.

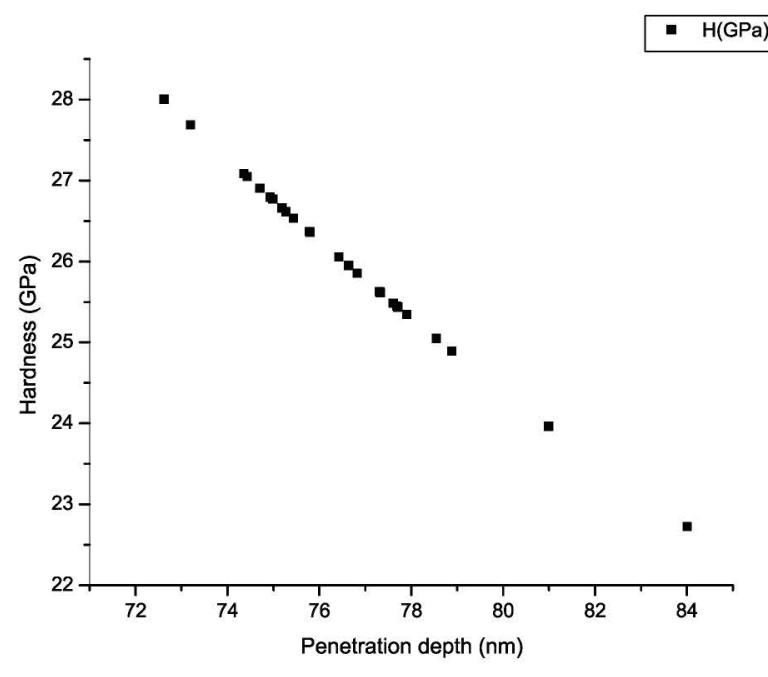




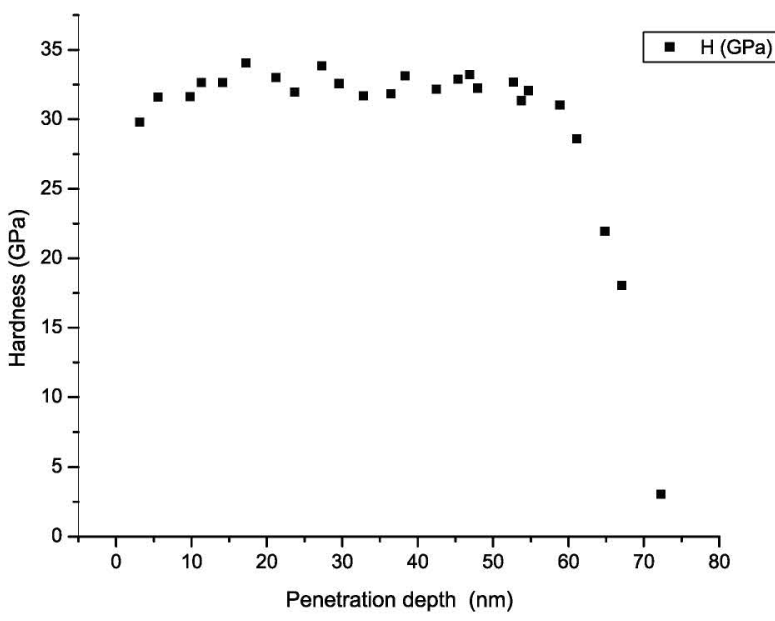

Figure 9. Nano hardness profile of the sub surface coating a) layer of CVD, b) sub surface of the TD.

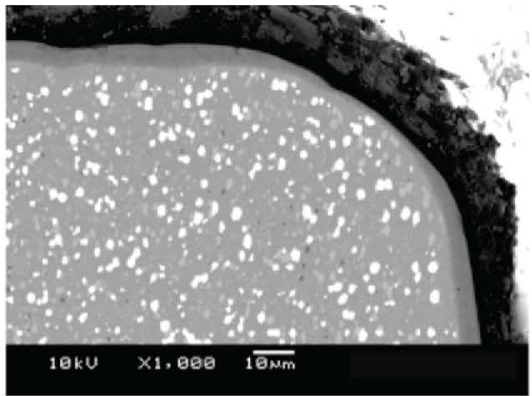

(a)

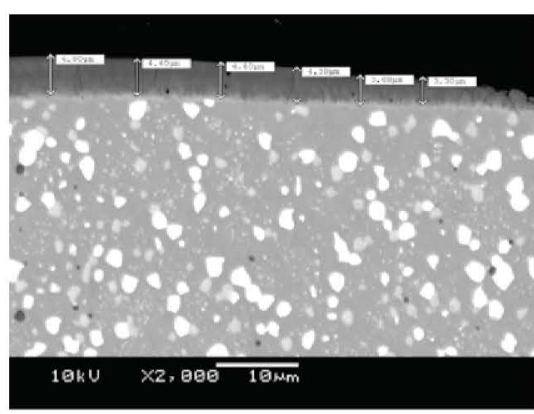

(b)

Figure 10. (a) Zone of the upper step, die E. (b) Thickness of the sub surface of TD.

\section{Conclusions}

The abrasive wear resistance of the coatings is related to the microstructure coatings deposited on metal base. It was found that the microstructure which has greater resistance to wear requires carbides nitrides $\mathrm{V} / \mathrm{Nb}$ and is obtained in the diffusion treatment. Electro erosion finish at the surface of the die affects the adhesion of the coating deposited by CVD and PVD. The layer deposited in the PVD coating has low wear resistance, in addition to not completely cover the work area of the die in the extrusion process.

\section{Acknowledgements}

The authors acknowledge the support provided by PROMEP 103.5/04/1371 \& ALCOA Inc. Mexico, during this work.

\section{References}

[1] PradipK. Saha. Aluminum Extrusion Technology, American Society for Metals International, Materials Park, Ohio 440730002, USA. Chapter 1 Fundamentals of Extrusion, pp. 1-28.

[2] B. H. Amstead, Ph. F. Ostwald, M. L. Begeman. Manufacturing Process, 7th ed. New York: John Wiley \& Sons. 1977.

[3] K. Laue and H. Stenger, Extrusion: Processes, Machinery, Tooling, American Society for Metals, (translated from the German version, A.F. Castle, Gernot Lang). Metals Park, Ohio. USA. 1981.

[4] Dies and Die Materials for Hot Forging "Hot Work Die Steels," Data Sheets, A. Finkl and Sons Company. 2005.

[5] V. Nagpal and T. Altan, Design and Manufacturing of Dies for Lubricated Extrusion of Shapes, J. Mech. Work. Technol., Vol. 1 (No. 2), Nov 1977, p 183

[6] J.A. Williams. Engineering Tribology. Department of Engineering, University of Cambridge. Oxford University Press Inc., New York. 1994.

[7] G.W. Stachowiak, A.W. Batchelor. Engineering Tribology, Tribology Series Vol. 24, Ed. Elsiever, Amsterdam, 1993.

[8] E. Rabinowicz. Friction and Wear of Materials; 2nd. Edition. New York: John Wiley \& Sons; 1995.

[9] A.E. Zeghni, M.S.J. Hashmi. The effect of coating and nitriding on the wear behaviour of tool steels. Journal of Materials Processing Technology. 2004.

[10] Thomas Björk, Richard Westergård, Sture Hogmark. Wear of surface treated dies for aluminium extrusion-a case study. Wear 249.2001.

[11] M. Terčelj, A. Smolej, P. Fajfar, R. Turk. Laboratory assessment of wear on nitrided surfaces of dies for hot extrusion of aluminium. Tribology International 40.2007.

[12] Instrumented Indentation Testing. J.L. Hay, MTS Systems Corporation. G.M. Pharr, The University of Tennessee and Oak Ridge National Laboratory. ASM Handbook Volume 08: Mechanical Testing and Evaluation. 2000. 